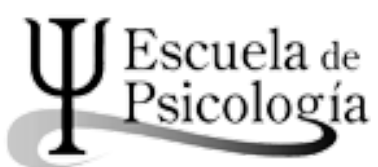

Wímb lu, Rev. electrónica de estudiantes Esc. de psicología, Univ. de Costa Rica. 11 (1): 19-38, 2016 / ISSN: 1659-2107

\title{
Terapias Cognitivas y Psicología Basada en la Evidencia. Su especificidad en el mundo infantil
}

Cognitive therapies and Evidence-Based Psychology. Specificity in children world.

Nadir Díaz Simón ${ }^{a}$

Hansel Soto Hernández $z^{b}$

Guillermo Ortega Castillo ${ }^{c}$

\begin{abstract}
Resumen: La Terapia Cognitiva es uno de los modelos en psicoterapia que más auge toman en la actualidad, principalmente por la fuerte relación que ha logrado desarrollar con la investigación y la prueba de sus hipótesis. El presente artículo se centra en ahondar en los orígenes, los postulados y cómo se ha logrado insertar en el Movimiento de la Práctica Basada en la Evidencia. Principalmente cómo se estructuran estos postulados en una de las poblaciones más complicadas, la de los niños y adolescentes.
\end{abstract}

Palabras clave: Teorías Cognitivas, Psicología Basada en la Evidencia, Psicoterapia Infantil

\begin{abstract}
Cognitive Therapy is one of the models in psychotherapy that take more popularity today, mainly because of the strong relationship that has developed with research and test their hypotheses. This article focuses on delving into the origins, principles and how it has managed to insert into the Movement of Evidence Based Practice. Specially how these principles are structured in one of the most difficult populations, children and adolescents.
\end{abstract}

Key Words: Cognitive Theories, Evidence-Based Psychology, Child Psychotherapy

\footnotetext{
a Centro de Neurociencias. Departamento de Neurocognición Escolar. Cuba. Correo electrónico: nadir.diaz@cneuro.edu.cu

b Hospital Clínico Quirúrgico Hermanos Ameijeiras. Departamento de Psicología. Cuba. Correo electrónico: hanselsoto@infomed.sld.cu

c Oficina Nacional de Administración Tributaria Isla de la Juventud. Cuba. Correo electrónico: guillermo@ijv.onat.gob.cu Recepción: 5/6/2015 Aceptación: 14/10/2015.
} 


\section{Introducción}

La perfección de los medios y la confusión de los fines parecen caracterizar esta época. Si deseamos sincera y apasionadamente la seguridad, el bienestar y el libre desarrollo de los talentos de todos los hombres, no careceremos de medios para alcanzar esta etapa. Aunque solo fuera una pequeña parte de la humanidad la que aspire a estos fines, su superioridad se manifestará a largo plazo.

\section{Albert Einstein (1879-1955)}

Desde tiempos inmemoriales el hombre trató de comprender los enigmas de la mente humana, cualquier trastorno o distorsión era considerado un efecto del demonio o espíritus malignos o por voluntad divina. Los chamanes, por ejemplo, eran personajes que tenían acceso al conocimiento y, a la vez, tenían el poder de curar enfermedades y modificar condiciones desfavorables para su tribu.

Estas dos motivaciones, la necesidad de reducir la incertidumbre intelectual y la de mejorar las condiciones de vida, siguen vigentes en el mundo contemporáneo con la misma fuerza que en nuestros antepasados. La única diferencia crucial es que el pensamiento y las interpretaciones mágicas de aquellas civilizaciones, imposible de ser contrastado empíricamente, cedió paso al pensamiento científico; que le incluye al interés por resolver preguntas los métodos sistemáticos para la contrastación lógica y empírica de sus afirmaciones o hipótesis. Por solo poner otro ejemplo, ya Plinio el Viejo, durante el primer siglo de la existencia de Roma, trataba de curar a aquellos que abusaban del alcohol colocando arañas muertas en descomposición en los vasos dónde bebían. Esta técnica en la actualidad es denominada condicionamiento aversivo.

En el siglo XVIII el "niño salvaje de Aveyron" fue enseñado a hablar con maniobras y técnicas que actualmente son conocidas como modelado, instigación, refuerzo positivo, retirada de reforzadores, etc. En el siglo XIX, el equivalente actual a un guardián de prisiones, Alexander Maconchi, usaba lo que conocemos hoy como economía de fichas, con el objetivo de conseguir que los internos del Royal British Penal obedecieran las reglas del penal. En el mismo siglo, un médico francés trató los pensamientos obsesivos con técnicas parecidas a lo que conocemos hoy como parada del pensamiento, o inhibición recíproca. No obstante, como orientación específica de intervención en salud, la Terapia Cognitivo-Conductual (TCC) aparece en la década de los 50 del siglo pasado, siendo aún una disciplina joven. (Ruiz, Díaz \& Villalobos, 2011).

En Psicología, esta tendencia a explicar los móviles de la conducta humana y sus posibles alteraciones de forma sistemática ha sido representada por las diferentes escuelas psicológicas, y por sus principales referentes prácticos, los modelos de psicoterapia. El objetivo del presente trabajo consiste en ofrecer algunas valoraciones críticas y ejemplificar con las llamadas psicoterapias cognitivas, uno de los modelos más coherentes, en nuestra opinión, de las propuestas actuales en psicoterapia.

Esclarecer parte de la esencia de este modelo, implica necesariamente destacar sus antecedentes filosóficos, epistemológicos, sus bases experimentales y eficacia en el tratamiento a determinadas enfermedades mentales. También nos proponemos explicar algunas de las especificidades de la terapia cognitiva en el contexto del tratamiento a niños, viendo su pertinencia y validez.

Nuestro interés fundamental radica en retomar los aspectos cognitivos en este tipo de psicoterapia, claro que esta no lo podemos analizar de forma aislada puesto que la cognición, la emoción y la conducta siempre se complementan como pares dialécticos. No obstante, intentaremos ponderar, al menos con fines didácticos, los elementos cognitivos en esta tríada.

Por otra parte, la salud mental de las personas en el período infanto-juvenil tiene importantes repercusiones en el desarrollo económico y social de los estados. Puesto que, por una parte, las enfermedades mentales de esta población requieren gran inversión de capital monetario y humano en los sistemas de salud (NHS, 1996). También la salud mental y el bienestar psicológico constituyen elementos que repercuten en de desarrollo económico de los pueblos a largo plazo. El concepto de capital mental abarca tanto recursos cognitivos y emocionales. Incluye la capacidad cognitiva de las personas; su flexibilidad y la eficiencia en el aprendizaje; sus habilidades sociales y la capacidad en el afrontamiento al estrés. Por tanto, el término abarca una dimensión clave de los elementos para establecer cómo un individuo es capaz de contribuir a la sociedad y experimentar una alta calidad de vida. En el período etario en que se centra este artículo, varias son las influencias que pueden afectar el bienestar y en el capital mental, e influir en el desenvolvimiento futuro de los sujetos (Beddington et al., 2008). Es por ello que cada vez la ayuda profesional debe ser lo más precisa y efectiva posible en esta etapa crítica para el desarrollo psicológico y social de los sujetos.

El término cognición procede del latín: cognoscere, que significa obtener conocimiento, acción y efecto de conocer. Así entendida, la cognición es el acto por el cual la persona logra saber y tener nociones acerca de sí y del mundo que le rodea a través de la experiencia. En este sentido, los filósofos griegos de la escuela estoica solían ya decir que "los hombres no se trastornan por los acontecimientos, sino por las opiniones que de ellos tienen". En la actualidad son múltiples las expresiones empleadas para señalar el papel que los factores cognitivos desempeñan en los trastornos emocionales (distorsión cognitiva, creencias irracionales, construcciones alteradas) (Castañeda, 1998).

La aplicación del paradigma cognitivo en psicoterapia, se ha apoyado en la idea anterior del filosofo Epicteto, maxima que responde a una de las mayores 
culturas, la griega, caracterizada por disímiles pensadores que comenzaron la carrera por el logos (el conocimiento) y por el entendimiento humano, recordemos la sentencia en el oráculo de Delfos: Conócete a ti mismo.

El fundamento de la terapia cognitiva, radica entonces, en el conocimiento de que todo proceso cognitivo ejerce grandes efectos en las emociones y en la conducta, y la distorsión de estos procesos (suposiciones, creencias) genera conductas inadaptadas y sentimientos negativos perturbadores.

Es una tarea difícil caracterizar en pocas palabras todo lo que es $y$, no menos importante, lo que no es la Terapia Cognitivo-Conductual. No obstante es importante la claridad conceptual, por lo que intentaremos más adelante exponer una definición. Clarifica en este sentido exponer los antecedentes de las psicoterapias cognitivas, luego de presentar en la cuestión filosófica, tratemos de indagar sobre los antecedentes empíricos de los cuales parte el modelo.

Según Minici, Rivadeneira \& Dehab (2001), la Terapia Cognitivo-Conductual posee algunos pilares teóricos básicos. El primero de ellos, surge a fines del siglo pasado a partir de las investigaciones del fisiólogo ruso Ivan Pavlov, quien accidentalmente descubre un proceso básico de aprendizaje que luego llamaría Condicionamiento Clásico. Muy sucintamente dicho, se trata de un proceso por el cual los organismos aprenden relaciones predictivas entre estímulos del ambiente. Sobre los trabajos de Pavlov es que se inspira uno de los autores más conocidos y más asociados con la Terapia Cognitivo-Conductual, justamente, John B. Watson, quien aplicando los principios del condicionamiento clásico para remitir la fobia de un niño, funda las bases de lo que luego se conoce como el Conductismo. $Y$ con respecto a esto vale la pena realizar algunas aclaraciones. El conductismo watsoniano representa actualmente más las bases metodológicas del modelo que un cuerpo teórico de principios explicativos de los cuales se deriven técnicas de intervención.

Resulta válido en estos autores destacar el valor del conductismo para las terapias cognitivas, más que un marco teórico, le brinda la metodología a seguir para demostrar sus planteamientos. Permitiéndonos una disgregación, consideramos que es este el principal legado del conductismo, sus propios autores hubieran sido menos criticados si hubieran reconocido la eficacia de su método y su alcance limitado, mas generalizaron sus resultados para explicar los móviles de la conducta humana y muchas variables intervinientes quedaron fuera.

Algunas de esas variables mediadoras, constituyen precisamente los esquemas mentales y representaciones, por eso se pude decir que la psicología cognitiva y su modelo terapéutico abrió de cierta forma la caja negra de los conductistas. $Y$ es que en efecto, comúnmente se realiza una distinción entre el "conductismo watsoniano o radical" y el "conductismo metodológico". Y en verdad, esto último es lo que hoy conservamos en Terapia Cognitivo-Conductual de los aportes de Watson; su énfasis en el comportamiento como tema de la psicología y en el uso del método científico como un modo de estudiarlo, nada más que eso. Luego hacia la década de 1960, según Minici Rivadeneira \& Dehab (2001), los trabajos encabezados por Albert Bandura comienzan a conformar un nuevo conjunto de hipótesis, cuyo énfasis recae en el papel que la imitación juega en el aprendizaje. Y sólo a manera de comentario, agreguemos que Bandura se halla también muy involucrado en la formulación de modelos cognitivos. De hecho, hacia la misma época, un movimiento quizás algo reaccionario al conductismo radical, comienza a estudiar los inicialmente denominados "eventos privados", vale decir, pensamientos, diálogos e imágenes internas, creencias, supuestos, por sólo nombrar algunos de los tópicos cubiertos por los así llamados "modelos cognoscitivos".

Como se puede apreciar en las propuestas anteriores existe una evolución de las terapias cognitivo-conductuales, las cuales exponemos a continuación. Según, los apuntes de Psicología de la UNED, Racham resumió la evolución conceptual de la TC en tres estadios, y O'Donohue en tres generaciones.

La primera generación de terapeutas está relacionada con las teorías de aprendizaje, el análisis conductual aplicado y el neoconductismo mediacional, en definitiva la extrapolación de los principios de aprendizaje a la clínica (tenemos en esta generación a Watson, Skinner, Thondike). La conducta normal y anormal se considera generada y mantenida por los mismos principios de aprendizaje. Las técnica de exposición, desensibilización sistemática, técnicas operantes, y biofeedback fueron desarrolladas en este periodo.

La segunda generación está marcada por la heterogeneidad y recoge a quienes tratan de superar deficiencias y limitaciones de las teorías de aprendizaje, aportando elementos de la psicología experimental, cognitiva y social (destaca aquí Bandura, Hull y Tolman). Con la segunda generación de terapeutas se produce el distanciamiento de los clínicos de la investigación básica sobre aprendizaje (más clínico y menos investigadores). Se aportó la teoría del aprendizaje social y las de enfoque cognitivo.

Y por último, la tercera generación de terapeutas (hasta la actualidad) buscan nuevas alternativas terapéuticas: concepto de multiplicidad de estímulos y contingencias, se intenta fomentar la relación entre la investigación básica y la aplicación clínica. A esta tercera generación pertenecen los nuevos desarrollos del enfoque cognitivo con carácter constructivista que se apartan de las bases racionalistas de los modelos cognitivos anteriores. La mayor parte de la práctica clínica está guiada por el empirismo (criterios de eficacia y efectividad), en esta generación podemos enmarcar las propuestas más contemporáneas de A. Beck y A. Ellis, las terapias cognitivas del estrés y el meta-modelo de programación neurolingüística, los cuales se explicarán más adelante. 


\section{Terapia Cognitiva-Conductual}

Luego de ahondar en los antecedentes de la psicoterapia cognitivaconductual estamos lejos de ofrecer una definición cerrada y conclusiva acerca de la misma, pero consideramos oportuno enunciar de manera somera algunos elementos claves.

Según Stallard (2001) el nombre de la TCC se utiliza para describir las intervenciones que tienen por objeto reducir el malestar psicológico y las conductas desadaptativas mediante la modificación de los procesos cognitivos.

La TCC se basa en el supuesto subyacente de que las emociones y las conductas (lo que sentimos y lo que hacemos) constituyen en su mayor parte un producto de las cogniciones (de lo que pensamos) y de que, en consecuencia, las intervenciones cognitivo-conductuales pueden generar cambios en la forma de pensar, sentir y actuar (Kendall, 1991). Esta incluye, los elementos esenciales tanto de las teorías cognitivas como de las teorías conductuales, y Kendall y Hollon (1979) la definen como una terapia que pretende preservar la eficacia de las técnicas conductuales si bien dentro de un contexto menos doctrinario, que incluye las interpretaciones cognitivas que realiza el niño además de sus atribuciones acerca de los acontecimientos. También se caracteriza por la aplicación clínica de la ciencia de la psicología, que se fundamenta en principios y procedimientos validados empíricamente (Plaud, 2001). (Citado por Ruiz, Díaz, \& Villalobos. (2011).

Aunque existen divergencias en las diferentes terapias cognitivas se pueden destacar principios comunes que comparten todas las orientaciones:

Primero: Es un ámbito de intervención en salud que trabaja con respuestas físicas, emocionales, cognitivas y conductuales desadaptadas, de carácter aprendido. Estas respuestas se han practicado a lo largo de tanto tiempo que se han convertido en hábitos del repertorio comportamental del individuo.

Sin embargo, los individuos no siempre conocen el carácter aprendido de sus hábitos y consideran que tienen poco o ningún control sobre ellos.

Segundo: Cuenta con técnicas y programas específicos para diferentes problemas y trastornos, cuya aplicación cuenta con un tiempo limitado en comparación con otras psicoterapias a largo plazo.

Tercero: Tiene en general una naturaleza educativa que puede ser más o menos explícita. La mayor parte de los procedimientos cuentan con módulos educativos, además de la conceptualización inicial del terapeuta sobre el problema y la lógica del tratamiento.

Cuarto: Posee en esencia un carácter auto-evaluador a lo largo de todo el proceso con continua referencia a la metodología experimental y énfasis en la validación empírica de los tratamientos. Estas características son herederas de la adopción del conductismo metodológico como principal eje vertebrador de la TCC, y probablemente la seña de identidad más genuina de la TCC actual. (Ruiz, Díaz \& Villalobos, 20011)

Los autores más reconocidos dentro este enfoque terapéutico son Albert Ellis (1913-2007) y Aaron Temkin Beck (1921-act), los cuales primero incursionaron en el psicoanálisis y posteriormente, derivaron hacia el cognitivismo, desarrollando sus respectivos modelos terapéuticos. (Zaldivar, 2013).

A grandes rasgos el modelo de la Terapia Racional Emotiva Conductual (TREC) de Ellis propone que la emoción y la conducta se derivan de la forma en que se interpreta lo que sucede, más que de lo que suceda en sí mismo o de acontecimiento per se. Según este modelo, los sucesos activadores (A, activating events) se valoran a la luz de las creencias ( $B$, beliefs), lo que genera a su vez unas consecuencias emocionales ( $C$, consequences). Las creencias pueden ser racionales $\mathrm{O}$ irracionales, y las creencias irracionales tienden a suscitar y perpetuar los estados emocionales negativos. (Stallard, 2001).

Por su parte el modelo de Beck, desarrollado a partir de sus trabajos sobre la depresión, (Zaldivar, 2013) que tiene su obra cumbre en Cognitive Therapy for Depression [Terapia cognitiva de la depresión] (Beck, 1976; Beck et al., 1979) propone que los pensamientos desadaptativos respecto de uno mismo, del mundo y del futuro (la llamada tríada cognitiva) inducen distorsiones cognitivas que generan sentimientos negativos.

El modelo presta una atención particular a los llamados supuestos o esquemas nucleares -esto es, a las creencias fijas que se desarrollaron y consolidaron durante el transcurso de la niñez y en relación con las cuales se evalúan los acontecimientos. Una vez activadas, estas creencias fijas generan una serie de pensamientos automáticos. Estos pensamientos y creencias automáticos pueden a su vez estar sujetos a una serie de distorsiones o errores lógicos, lo que contribuye a asociar un mayor número de cogniciones negativas al estado de ánimo deprimido. (Stallard, 2001).

Los procedimientos de intervención de ambos autores fueron muy influenciados por de la corriente semántica-cognitiva, que establece que las creencias, las expectativas, las atribuciones y otras actividades cognitivas son centrales para producir, predecir y comprender la conducta psicopatológica y los efectos de la intervención terapéutica. (Ramallo, 1981).

Otras de las reconocidas propuestas dentro de la TCC es la Técnica de Inoculación al Estrés de Donald Meichenbaum en donde el terapeuta prepara a los pacientes para una situación de la vida real que presuponen que será estresante o para exponerse a una situación que el terapeuta está creando para insensibilizar al paciente con miras a una situación estresante. Cuanto más detallada y realista 
sea la situación creada por el terapeuta en la práctica, será más probable que el paciente esté inoculado contra el estrés en la situación real. Ayuda al paciente a preparar una lista de los pensamientos negativos y del diálogo interno que emergen al enfrentarse a una situación estresante.

Según Meichenbaum y Cameron (1980) (Citado por Ramallo, 1981). Las principales diferencias entre las propuestas de las TCC se refieren a:

1. La base teórica de los procedimientos puede ser muy variada (condicionamiento clásico u operante, procesamiento cognitivo de la información, aprendizaje social, etc.).

2. Pueden ser considerados aspectos diferentes de la experiencia cognitiva (creencias, atribuciones, expectativas e imágenes, solución de problemas, etc.).

3. Considerable variabilidad respecto al mejor punto de intervención en el complejo cognición - afecto - conducta - consecuencias.

4. Diferentes estrategias para la intervención (ataque frontal a las creencias irracionales, contraste empírico de las creencias, etc.).

5. Diferencias respecto al estilo de la intervención (desde la directiva a la colaboradora).

6. En relación al énfasis dado al uso explícito de los procedimientos de la terapia de conducta, pueden encontrarse diferencias muy notables, etc.

\section{Discusión}

Una de las peculiaridades de las terapias cognitivas es la estrecha relación que guardan con la investigación básica, desde sus inicios han sido unas de las más consecuentes con un modelo contemporáneo que cada vez cobra más fuerza, la Psicología Basada en la Evidencia (PBE). En nuestra opinión, una terapia que obvie alimentar su modelo con nuevos resultados investigativos está condenada a las descripciones superfluas y al desconocimiento de las esencia de los trastornos mentales. Analicemos a continuación esta propuesta cognitiva-conductual partiendo de su basamento teórico.

Nuestra experiencia intuitiva nos revela que pensamos con palabras e imágenes mentales. Según el referido libro de Introducción a la Psicología Cognitiva (de Vega, 1984): los estudios sobre representaciones mentales proponen que existe un único formato representacional abstracto, semántico y proposicional que subyace como sustrato común de las palabras e imágenes. Por consiguiente, las imágenes mentales han mostrado ser un eficaz mediador cognitivo en el tratamiento de algunos trastornos psíquicos. Así la desensibilización sistemática ideada por Wolpe (1958) para el tratamiento de fobias, neurosis de ansiedad y trastornos sexuales emplea una jerarquía de situaciones ansiógenas que el sujeto debe imaginar vívidamente al tiempo que aprende una respuesta incompatible de relajación.

En otras palabras, mediante la presencia de estímulos que inducen miedo se aprende un segundo estímulo que genera una respuesta antagónica (la relajación), siendo posible la inhibición gradual de la respuesta del miedo. En la actualidad el procedimiento se utiliza ampliamente en la práctica clínica e incluye la exposición gradual, en vivo y en la imaginación, a una serie jerarquizada de situaciones temidas al tiempo que es mantenida la respuesta de relajación.

La propuesta de Wolpe es un ejemplo de la coherencia teoría método que hablamos en un inicio que tienen las TCC. Como basado en la teoría del formato de las representaciones mentales, se proponen técnicas conductuales que van a crear nuevas esquemas mentales más adaptativos a la vida de los pacientes. Se demuestra así que Wolpe en su modelo utilizó estrategias experimentales (por ejemplo el resultado de Paivio del formato representacional) para validar sus tratamientos desde sus comienzos.

Según Mustaca, (2003), en los últimos años se ha puesto énfasis en el estudio de la eficacia de las intervenciones psicológicas, estableciéndose pautas rigurosas para su validación empírica que se fundamentan en el método científico. Se halló que más del $80 \%$ de las terapias con apoyo empírico (TAE) pertenecen al enfoque comportamental o comportamental cognitivo, tanto en adultos como ancianos, niños y adolescentes. Si se agregan otro tipo de terapias que también usan en la práctica herramientas cognitivas - comportamentales, pero tienen un marco teórico diferente, el porcentaje aumenta al $96 \%$. Estas estrategias surgieron a partir de la investigación básica con animales no humanos y humanos, en especial del aprendizaje y del conductismo. De este modo se evidencia la importancia crucial que tiene la investigación básica para la ciencia aplicada.

La PBE constituye un paradigma contemporáneo de acción en la ciencia psicológica. Esta dada por la necesidad de disponer de herramientas fiables de comunicar información fiable que se apoye en datos empíricos contrastados (Chambless \& Hollon, 1998) que junto con el juicio del experto faciliten y aseguren el desarrollo y aplicación de diagnósticos e intervenciones válidos, mejorando la toma de decisiones ante los problemas clínicos. (Frías-Navarro, Pascual-Llobell, \& García-Pérez, 2002).

Este modelo de investigación tiene sus raíces en un modelo médico (Medicina Basada en la Evidencia) que comenzó a gestarse en la segunda mitad del siglo pasado. Este se vio potenciado por la demostración de la falta de fundamento de muchas decisiones clínicas y de la enorme variabilidad de la práctica médica. En 1992 el grupo de trabajo Evidence-Based Medicine Working Group publicaron en 
el Journal of the American Medical Association (JAMA) (268:2420-5) el artículo fundacional de la Medicina Basada en la Evidencia (MBE) proponiendo un cambio de paradigma para la práctica de la medicina que exige la adquisición de nuevas habilidades por parte del profesional: la búsqueda de la mejor evidencia científica, evaluar y jerarquizar la evidencia disponible e integrarla con la propia experiencia del profesional para ofrecer al paciente las mejores alternativas.

Impulsado por el Movimiento de la Práctica Basada en la Evidencia la Asociación Americana de Psicología (APA, por sus siglas en inglés) en 1992 crea la Junta de Asuntos Profesionales (Board of Professional Affairs), y el Comité de Avances de la Práctica Profesional (Committee for the Advancement of Professional Practice). El documento desarrollado por estos organismos (Template for Developing Guidelines: Interventions for Mental Disorders and Psychosocial Aspects of Physical Disorders) fue aprobado en 1995. En el mismo se describen la variedad de evidencias que deben ser consideradas para que cada práctica clínica emergente se base en datos de investigaciones y en la experiencia en la experiencia clínica (APA Presidential Task Force on EvidenceBased Practice, 2006).

La evaluación de la eficacia de las intervenciones terapéuticas es una necesidad imperante. En primer lugar, porque el progreso científico de la psicología clínica requiere la delimitación de las terapias eficaces, así como de los componentes activos de las mismas. En segundo lugar, porque esta disciplina se enfrenta, como fruto de su propio desarrollo, a retos de cada vez mayor complejidad (por ejemplo, al tratamiento de los trastornos de personalidad, de los problemas de la conducta alimentaria o de las nuevas adicciones y de las nuevas situaciones que le impone la complejidad de la realidad contemporánea). Y en tercer lugar, porque las terapias psicológicas están ya incorporadas a los Centros de Salud. De este modo, los servicios de salud mental sólo debe ofertar terapias efectivas (más allá de un efecto placebo o de los efectos inespecíficos de cualquier terapia) $y$, en igualdad de condiciones, breves para acortar el sufrimiento del paciente y ahorrar gastos y tiempo a estos centros.

Por eso ya no es suficiente afirmar que un tipo de terapia es eficiente para un tipo de problemática, sino que, por las condiciones objetivas en las que nos desarrollamos, es necesario presentar una serie de evidencias que muestren que dicha propuesta es la más eficiente para determinado tipo de situaciones. Para ello se han propuesto y normalizado niveles de evidencias (Tabla 1) para las pruebas empíricas.
TABLA 1.

Nivel de evidencia

\begin{tabular}{ll}
\hline NIVEL DE EVIDENCIA & TIPO DE ESTUDIO \\
\hline Mínima & - Descripción de casos únicos \\
& - Estudios descriptivos o resoluciones \\
de comités de expertos \\
• Estudios de caso controlado \\
• Ensayos controladosy aleatorizados \\
con muestras pequeñas \\
• Ensayos controladosy aleatorizados \\
con muestras grades \\
- Meta-análisis de ensayos \\
controlados y aleatorizados con \\
muestras suficientemente grandes
\end{tabular}

Tomado de Echeburúa, E., Salaberría, K., de Corral, P., \& Polo-López, R. (2010). Terapias psicológicas basadas En la Evidencia: Limitaciones y retos de futuro. Revista Argentina de Clínica Psicológica, XIX, 247-256.

Se hace necesario entonces la aplicación de estudios bien diseñados, de tipo comparativos y longitudinales, que estén enfocado a obtener la evidencia, el material empírico y el respaldo experimental (eficacia) sobre el cual se asentará después el cuerpo teórico de una determinada terapia. Según referencias de los autores anteriores, ofrecemos un buen ejemplo en este sentido (op.cit.): Barlow y Hersen (1984) mencionaron 76 investigaciones que probaron la eficacia de la intervención TCC. Los estudios se extienden al tratamiento de niños de 20 semanas a 14 años, en distintos ámbitos (escuelas, hospitales, hogares, centros de rehabilitación, guarderías, etc.), con distintos terapeutas (psicólogos, psiquiatras, padres, maestros, enfermeras, etc.) y aplicada a diversos trastornos (conducta perturbadora, oposición, autolesión, agresividad, delincuencia, enuresis, falta de atención en clase, succión del pulgar, tos, autismo, etc.). Estos datos sugieren fuertemente que la atención diferenciada está suficientemente validada como para ser aplicada con éxito. Esta estrategia probablemente no se habría desarrollado sin los resultados de la psicología experimental, ya que es un tratamiento contra intuitivo. 
Si sería oportuno destacar que la importancia de utilizar el método científico - los diseños experimentales para estudiar la eficacia de las intervenciones psicológicas no es reciente, ni exclusivo a las TCC, sin embargo sus postulados teóricos de base le permiten nutrirse mucho de estos estudios a diferencias de otros enfoques, como el psicoanálisis por ejemplo. Ahora bien, está claro que los fines de la investigación y la psicoterapia son diferentes, pero somos de la opinión, de que ambas deben ir de la mano y no ir separadas como sucede muy a menudo en Psicología, porque como bien diría el epistemólogo Mario Bunge: "El filósofo o psicólogo que no está al día con la ciencia se condena a hablarles a los muertos y confundir a los vivos".

En otro orden de cosas, haciendo un corte transversal de las diferentes propuestas de TCC presentadas en este ensayo podemos coincidir que existen ciertas técnicas o estrategias terapéuticas comunes. Las mismas son, entrenar al paciente para que: controle sus propios sentimientos, aprenda a relajarse, realice ejercicio físico, tenga una respiración controlada, proyecte imágenes tranquilizantes, realice actividades relajantes y prevenga las situaciones desbordantes de sus recursos cognitivos.

Sin embargo lo anterior cobra diferente significado en el ámbito de la psicoterapia infantil y sobre la especificidad de la TCC en la intervención con niños trataremos a continuación.

\section{La TCC en el mundo infantil.}

En toda psicoterapia la comunicación es una de las herramientas principales, poder participar en una interacción fluida y adaptada a las necesidades del paciente es fundamental para el logro de los objetivos. En los tratamientos con niños esto se vuelve un desafío especial para los terapeutas ya que el uso de un lenguaje adulto puede problematizar el establecimiento de una apropiada alianza terapéutica y el aprovechamiento de las mediaciones. Así mismo, suele ser difícil para el adulto utilizar un lenguaje acorde al nivel evolutivo e intereses del paciente. Por lo tanto, existen importantes restricciones a la implementación de un tratamiento cognitivo comportamental tradicional cuando se trabaja con niños:

Las nociones de causalidad se desarrollan en manera rudimentaria, pudiendo aplicarse solo a aquellas situaciones en las cuales el niño participa en el momento presente.

Reflexionar acerca de las consecuencias de su propia conducta, elemento esencial a toda terapia cognitiva, puede constituir un desafío que exceda las capacidades del paciente.
La perspectiva egocéntrica de los niños dificulta la reflexión sobre las necesidades y motivaciones de los otros, y la diferenciación e interrelación de sus conductas, pensamientos y emociones.

Por último, las diferencias en su capacidad atencional, memoria y motivación limitada harían impracticable un enfoque abstracto y demasiado formal (Grave y Blisset, 2004).

Shaffer (1996) (Citado por Grave \& Blisset, 2004) afirmó que la producción de adaptaciones en las formas verbales utilizadas y en la modalidad de las preguntas, pueden ayudar a sortear diversas particularidades del desarrollo, permitiendo la toma de perspectiva social, la reflexión respecto a diversos estados emocionales y la capacidad de entender que las creencias.

Dentro de las evidencias empíricas de estudios que han utilizado modificaciones a las terapias clásicas, que intentan adaptar las intervenciones al período evolutivo de los infantes, se destaca el realizado por Heffner, Greco y Eifert (2003). Donde se plantearon investigar la preferencia y el mayor compromiso de los niños en la implementación de instrucciones de relajación metafórica en comparación a las literales. Los resultados apuntan a que existe una preferencia de los niños y las niñas por las instrucciones de relajación metafóricas.

Tal vez uno de los ejemplos más claros del efecto motivacional que tiene el uso de metáforas puede hallarse en el tratamiento del trastorno obsesivo compulsivo pediátrico. Ejemplos de ello son el protocolo de tratamiento desarrollado por March y Mulle (1998), y el modelo de abordaje de Pinto Wagner (2003). La terapia cognitiva conductual es considerada como el tratamiento de primera elección para los niños con TOC tanto severo como moderado (March, Frances, Carpenter y Kahn, 2007) (Citado por Grave \& Blisset, 2004)

March y Mulle (1998) desarrollaron un protocolo para el tratamiento del TOC en niños y adolescentes, donde se implementa la "externalización del problema" descripta por White, Epston y otros (Freeman, Epston y Lobovits, 2001). La misma consiste en trazar una analogía entre el trastorno y un enemigo monstruoso al que se tiene que enfrentar.

En un estudio piloto realizado con adolescentes de 13 a 17 años realizado por Thienemann y col. (2001) que se basaba en dicho modelo observaron una serie de datos que apoyarían las hipótesis propuestas acerca del uso de las metáforas. En primer lugar se observó una mejoría clínica y estadísticamente significativa en la sintomatología obsesiva compulsiva medida por la Children's Yale-Brown Obsessive Compulsive Scale. Al mismo tiempo, una consistente involucración en el diseño de exposiciones. Y por último, en medidas de auto informe se confirmó la satisfacción de los adolescentes con dicha terapia.

Pinto Wagner (2003) por su parte ha propuesto importantes aportes a la adaptación de la TCC en niños para el tratamiento del TOC. Realizó un protocolo sensible al desarrollo de los niños donde se explican las intervenciones mediante 
diversas metáforas. Por ejemplo, el concepto de habituación que se da durante la exposición y prevención de respuesta se explica como "la dificultad que se encuentra al querer subir una montaña en bicicleta". "Cuesta arriba puede resultar difícil pero luego cuesta abajo resulta más sencillo". La sensación de domino sobre el TOC que se genera una vez finalizada la exposición se traduce como la sensación que se encuentra luego de haber superado "la montaña de la preocupación".

Se han publicado varios estudios que indican la utilidad y efectividad de la TCC para numerosos trastornos psicológicos, e incluso físicos, alrededor del mundo. En 2001, Chambless \& Ollendick revisan varias investigaciones que identifican intervenciones psicológicas empíricamente validadas o Tratamientos con Apoyo Empírico (TAE).

El estudio mostró que en las investigaciones compiladas, los procedimientos y técnicas cognitivos y conductuales son las intervenciones de elección específicas más útiles y efectivas para la mayor parte de los problemas de salud mental, tanto en adultos como en niños (a veces en combinación con la terapia farmacológica). En niños: en trastornos de conducta, fobias, depresiones, trastorno de déficit de atención con hiperactividad, enuresis, encopresis, trastornos de ansiedad y evitativo, retraso mental, autismo, etc. Asimismo, la TCC ha mostrado ser eficaz en la atención de algunas afecciones físicas como la demencia, los dolores crónicos por enfermedad reumática, los efectos colaterales de la quimioterapia para pacientes con cáncer; fibromialgia, diabetes, obesidad, migraña, entre otras.

El tratamiento para el niño que ha sufrido de abuso sexual es a menudo un proceso difícil en que el niño y su familia deben pensar y confrontar recuerdos y materiales incómodos. Los GB-CBT (juegos basados en la terapia cognitiva) usan técnicas y estrategias que proporcionan la motivación, el interés, y crea una caja fuerte y el contexto agradable para procesar el trauma.

Los estudios sobre CBT en niños que han sobrevivido a traumas en su infancia, registran la existencia de varios componentes terapéuticos críticos, tales como: la identificación emocional, expresión y habilidades de la regulación, el conocimiento sobre el abuso, la exposición gradual a los estímulos abuso-específicos y las habilidades de seguridad personales. (Colectivo de Autores, 2004).

Este tipo de terapia también ha sido utilizada en casos de violación infantil, como alternativa al enfrentamiento del Trastorno de Estrés Postraumático (TEPT) se realizó un tratamiento cognitivo conductual consistente en la integración de técnicas de desensibilización sistemática, relajación, psicoeducación y control del pensamiento. Los resultados dan cuenta que el tratamiento fue exitoso ya que disminuyeron los síntomas intrusivos, evitativos y de aumento de la activación (Guerra \& Plaza, 2009). Estos resultados parecen documentar que el cuidadoso uso del lenguaje, adaptado a las particularidades evolutivas y a los intereses usuales de los niños colabora en transformar la terapia en un entorno de aprendizaje adecuado.

Desde la epistemología evolutiva se entiende que todo proceso de aprendizaje significativo se realiza en un nivel de discrepancia óptimo: los estímulos emitidos en el ambiente de aprendizaje plantean problemas cuya resolución favorece el desarrollo del conocimiento, pero han de ser lo suficientemente adecuados al funcionamiento lógico actual para que puedan ser asimilados por las estructuras cognitivas preexistentes.

El razonamiento puede ser demostrado implementando atrapantes historias, analogías y metáforas. A partir de estas, conceptos abstractos como los factores causales adquieren una forma concreta y los procesos introspectivos pueden observarse de manera externa. Las limitaciones de conocimiento, memoria y motivación son superadas a partir del aprovechamiento de personajes, escenarios y situaciones interesantes para el niño.

El desafío del terapeuta cognitivo comportamental infanto-juvenil consiste en encontrar la metáfora apropiada para el nivel evolutivo del paciente y construir una narrativa terapéutica alrededor de la misma, teniendo en cuenta sus intereses (Grave y Blisset, 2004).La implementación de metáforas en el proceso terapéutico permite durante la etapa de evaluación la co-construcción de la alianza terapéutica, facilitan al niño la comprensión de cuál es el rol del terapeuta, y permite acceso a la información necesaria para el diagnóstico y la conceptualización.

Durante el tratamiento, las metáforas pueden servir para explicar determinadas estrategias y volverlas más atractivas para el niño, logrando así una mayor adherencia a las mismas, y en la fase de cierre del tratamiento apuntan a lograr una mayor consolidación de las técnicas y estrategias adquiridas por el paciente. Es necesaria la utilización de palabras familiares que se relacionen con la problemática, y a la vez susciten el interés del niño. Por ejemplo, Para niños con trastornos de ansiedad: Doctores del miedo, expertos en valentía.

Uno de los ingredientes activos del tratamiento cognitivo-conductual es el desarrollo de la capacidad de auto-observación en las situaciones problemáticas. Su simplificación y adaptación a un formato atractivo resulta crucial para ser aceptado por los niños. De esta manera se elude la formalidad de la "tarea terapéutica" para transformarse en un juego de afrontamiento plausible de ser implementado en los momentos conflictivos. Las metáforas e imágenes no solo constituyen un puente para la comprensión en la comunicación interpersonal. Apuntan también a transformar en actividades lúdicas y estimulantes las propuestas terapéuticas.

Ciertas perspectivas plantean la finalización de los tratamientos de forma tal que se certifiquen los logros alcanzados revisando los recursos que el paciente utilizó para llegar a su meta. El uso de diplomas, cartas y grabaciones de video documentan habilidades y características personales que los niños y sus familias 
pueden implementar, con independencia del espacio terapéutico, en actividades de afrontamiento que continúan día a día.

No obstante, advirtamos que, la idea de la generalización en la aplicación de este u otro tipo de tratamiento, debe ser manejado con especial cuidado, ya que no existen estudios lo suficientemente extensos que permitan de forma categórica indicar esta metodología de trabajo a una población especifica en el universo infantil, o en cualquier otro.

Consideramos que siempre una intervención debe ser el resultado de un minucioso proceso de diagnóstico y evaluación conductual, de forma de determinar si el tratamiento más apropiado para la persona atendida es de orientación cognitivo conductual o de otra orientación. En este sentido, se considera que la psicoterapia debe ser dirigida a las necesidades de cada paciente en particular, por lo que la aplicación apresurada y/o automatizada de cualquier tipo de intervención puede ocasionar serios perjuicios para los pacientes, como por ejemplo, el retroceso en su proceso de recuperación.

\section{Críticas}

Como toda propuesta psicológica, la TCC no ha estado ajena a críticas y objeciones. A continuación mostramos un grupo de detracciones que le han formulado a esta propuesta de intervención psicológica y las respuestas que han brindado los defensores de este enfoque.

Una de las frecuentes es la referida a que el tratamiento y la supresión de los síntomas son puramente superficiales, y que éstos se retornarán más adelante o se sustituirán por otros. Continuando con la línea de pensamiento que hemos defendido se muestra que gran cantidad de estudios de seguimiento que ha mostrado que la mayoría de las veces este fenómeno no se produce.

Las recaídas corresponden generalmente a trastornos en los cuales ninguna estrategia psicológica ha obtenido una eficacia significativa permanente, por ejemplo, en la esquizofrenia o el trastorno antisocial de la personalidad. Los índices de eficacia de la TCC para síndromes de altísima incidencia, como los trastornos de ansiedad, rondan el $90 \%$ de casos recuperados o muy mejorados en estudios de seguimiento a más de 2 años. No obstante, en las adicciones a sustancias psicoactivas, los índices de eficacia bajan abruptamente; sólo el $50 \%$ de los pacientes atendidos en comunidades terapéuticas que operan con los principios de la TCC se mantienen abstinentes por más de 2 años. Aunque desalentadoras, estas cifras son las más elevadas que hasta la actualidad se han reportado en lo que a adicciones se refiere.

También se le acusa de mecanicista; de sólo tratar las conductas, y de relaciones de Estímulo - Respuesta entre fenómenos, y no de la subjetividad o de los aspectos más profundos y complejos de cada individuo; por lo tanto proponen soluciones homogéneas y totalizadoras, ignorando las particularidades personales. Esta limitación radica en la dificultad del estudio científico de los fenómenos mentales "subyacentes", que consiste en su inaccesibilidad a la observación, la medición y el registro. El lenguaje, la conducta verbal, su adquisición y funciones, dan cuenta de los fenómenos mentales internos. El conductismo trata los aspectos subjetivos como funciones del lenguaje o conducta verbal. No obstante, un punto flaco de las "terapias conductistas" ha sido su descuido en el abordaje de los trastornos de la personalidad, situación que ya se revierte de un tiempo a esta parte.

Muy relacionado con el anterior punto se plantea que los enfoques científicos experimentalistas, reduccionistas o biologisistas no son los mejores métodos para el estudio de los problemas y avatares humanos; al respecto tienen más que aportar la filosofía, la sociología, la antropología, la lingüística y otras construcciones y disciplinas culturales. Acaso ¿Es ético que, conociéndose la eficacia de determinadas técnicas terapéuticas disponibles, un psicólogo las ignore o se niegue a su implementación por el hecho de adherir a un marco teórico diferente? ¿Es justificable el sufrimiento de las personas y el mantenimiento de sus problemas cuando las investigaciones señalan la utilidad de procedimientos específicos para contrarrestarlos? ¿Por qué negarse a utilizarlos? ¿No sería razonable al menos preguntarle al paciente si desea que tales procedimientos le sean aplicados?

Normalmente, la persona que recurre a un profesional de la salud mental en busca de ayuda psicológica no se halla al tanto de la diversidad de enfoques existentes en el campo de la clínica; desea únicamente que el terapeuta la ayude a resolver los problemas que le ocasionan sufrimiento, de la manera más sencilla y rápida posible: una terapia eficaz. Lamentablemente, muchos psicólogos parecieran no darse cuenta de este hecho tan obvio y de puro sentido común: El pedido de efectividad no es escuchado. (Leiva, 2004).

\section{Conclusiones}

Luego de haber realizado todo este análisis podemos sintetizar y formular nociones particulares de lo planteado hasta el momento. Primeramente, que las ideas planteadas por la Terapia Cognitiva-Condctual han sido manejas y utilizadas desde los inicios de la civilización humana, mucho antes de los postulados psicológicos oficiales que sistematizaron y estructuraron esta propuesta nacieran, la cual es heredera de todo un conocimiento empírico anterior.

Esta propuesta de hacer psicoterapia se desprende y evoluciona de las propuestas más antiguas en psicología. Sus raíces históricas más profundas tienen 
sitio en los postulados y teorías que dieron a la Psicología un estatus de ciencia independiente, las cuales han sido ampliadas y enriquecidas por un conjunto de autores que han tratado de mantener la cientificidad de sus postulados.

La TC, lejos de ser el non plus ultra de la psicoterapia intenta caracterizarse por la aplicación en el ámbito clínico de las investigaciones fundamentados en principios y procedimientos validados empíricamente, con el objetivo de aumentar la eficiencia y eficacia en los tratamientos.

La TC ha demostrado gran efectividad en trastornos donde la ansiedad o la depresión es el principal problema y en los tratamientos psicológicos para casos moderados y graves de depresión.

Por último planteamos que este tipo de técnicas y procedimientos ha sabido adaptarse a las especificidades de las etapas del desarrollo en niños y adolescentes, echando mano de la actividad lúdica como mediador en el tratamiento de tipos específicos de problemáticas de índole psicológico.

\section{Referencias Bibliográficas}

APA Presidential Task Force on Evidence-Based Practice (2006). EvidenceBased Practice in Psychology. American Psychologist, 61(4), 271-285. doi: 10.1037/0003-066X.61.4.271.

Castañeda, P.F. (1998). Modelos de psicoterapia conductual y cognitiva frente a la conducta desadaptada. Revista de Psicología, 2(1).

Beddington, J., Cooper, C. L., Goswami, U., et al. (2008). The mental wealth of nations. Nature, 455(October), 1057-1059.

Centro de Adicciones y Salud Mental. (2011). Terapia cognitivo-conductual para individuos de origen latinoamericano: Manual para aumentar la eficacia de la TCC para individuos de origen latinoamericano en Canadá. (CAMH) English la TCC para individu
(p. 94). Toronto.

Chambless, D.L. \& Hollon, S. (1998). Defining empirically-suported therapies. Journal of Consulting and Clinical Psychology, 66, 7.18.

Colectivo de Autores (2004). How to Implement Cognitive Behavioral Therapy (TF-CBT) How to Implement Trauma-Focused Cognitive Behavioral Therapy. Los Angeles: National Child Traumatic Stress Network.

De Vega. (1994). Introducción a la Psicología Cognitiva. La Habana: Editorial Félix Varela.
Echeburúa, E. (1998). ¿Qué terapias psicológicas son eficaces? Revista de Psicopatología y Psicología Clínica, 3(3), 149-160.

Echeburúa, E., Salaberría, K., de Corral, P., \& Polo-López, R. (2010). Terapias psicológicas basadas en la Evidencia: Limitaciones y retos de futuro. Revista Argentina de Clínica Psicológica, XIX, 247-256.

Frías-Navarro, M. D., Pascual-Llobell, J., \& García-Pérez, J. F. (2002). Concepto de método de la Psicología basada en la evidencia. III Congreso Virtual de Psiquiatría.

Grave, J. y Blisset, J. (2004). Is cognitive behaviour therapy developmentally appropriate for young children? A critical review of the evidence. Clinical Psychology Review, 24, 399-420.

Guerra, C., \& Plaza, H. (2009). Tratamiento Cognitivo-Conductual del Estrés Postraumático en un caso de violación infantil. Revista de Psicología, XVIII(1), 103-130.

Heffner, M., Greco, L.A. y Eifert, G.H. (2003). Pretend you are a turtle: Children's responses to metaphorical and literal relaxation instructions. Child Family and Behaviour Therapy, 25, 19-33.

Leiva, C. (2008). Respuestas a algunas objeciones y críticas a la terapia cognitivoconductual. Boletín Electrónico de Investigación de la Asociación Oaxaqueña de Psicología, 4, 57-65.

March, J. y Mulle, K. (1998). OCD in Children and Adolescents. New York: The Guilford Press.

Minici, A., Rivadeneira, C., \& Dehab, J. (2001). ¿Qué es la Terapia Cognitivo Conductual? Revista de terapia cognitivo conductual, 1(junio), 1-6. Disponible en: http://revista.cognitivoconductual.org/

Mustaca, A. E. (2003). Tratamientos psicológicos eficaces y ciencia básica. Revista Latinoamericana de Psicología, 1-23.

NHS Executive, Department of Health (United Kingdom) (1996). Burdens of disease: a discussion document. London, Department of Health.

Ramallo, F. B. (1981). Las terapias cognitivos-conductuales: Una revisión. Estudios de Psicología, 7, 92-114.

Ruiz, M., Díaz, M., \& Villalobos, A. (2011). Manual de Técnicas de Intervención Cognitivo Conductuales. Madrid: Panorama Desclée. 
Springer, C., Misurell, J.R., \& Hiller, A. (2012). Game-Based Cognitive-Behavioral Therapy (GB-CBT) group program for children who have experienced sexual abuse: A three-month follow-up investigation. Journal of Child Sexual Abuse, 21(6), 646-64. Doi: 10.1080/10538712.2012.722592.

Stallard, P. (2001). Pensar bien-Sentirse bien: Manual práctico de terapia cognitivoconductual para niños y adolescentes. EUA: Editorial Desclée de Brawer.

Zaldívar, D.F. (2013). Práctica psicoterapéutica. La Habana, Cuba: Editorial Félix Varela.

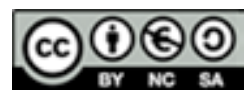

Esta obra está bajo una licencia de Creative Commons Reconocimiento

- NoComercial - CompartirIgual (by-nc-sa) 